\title{
Cien años de historia y treinta en conjunto
}

\section{One hundred years of history and thirty together}

\author{
Manuel Garza-León ${ }^{1 *}$, Everardo Hernández-Quintela², Gerardo García-Aguirre³, \\ Roberto González-Salinas ${ }^{3}$ y Óscar Guerrero-Berger ${ }^{3}$ \\ ${ }^{1}$ Editor Jefe actual; ${ }^{2}$ Editor Jefe 2009-2012; ${ }^{3}$ Coeditor actual. Revista Mexicana de Oftalmología, Sociedad Mexicana de Oftalmología, Ciudad de \\ México, México
}

El secreto de mi éxito fue rodearme de personas mejor que yo Andrew Carnegie

La Asociación para Evitar la Ceguera en México (APEC) cumple este año sus primeros 100 años de historia. Para festejar este importante logro, en este volumen de la revista, los doctores Sánchez Huerta, Sánchez Fontán y Salcedo Casillas publican una breve reseña de los principales acontecimientos que han dado lugar a uno de los hospitales oftalmológicos más importantes de nuestro país. Este artículo de historia abarca desde la concepción de la asociación por los doctores José de Jesús González y José Terrés y su fundación el 13 de agosto de 1918. En él se describen las diferentes labores asistenciales, la misión comprometida de ayuda al desprotegido, con un alto grado de sentido humanista, el proceso dialéctico de la contribución científica y tecnológica a la sociedad, y los diversos espacios físicos con los que ha contado, finalmente, hacen un recuento de lo que hoy es la APEC y la visión a futuro que los guía.

Sin duda, la historia de la APEC va íntimamente ligada a la historia de la Revista Mexicana de Oftalmología (RMO). Como mencionamos en el editorial del volumen anterior $^{1}$, la RMO surge de la unión de los Anales de Oftalmología (ISSN 0187-4519 Ann de Oftalmol) con los Archivos de la Asociación para Evitar la Ceguera en
México (ISSN 0004-489X Arch Asoc Evit Ceguera $M e x)$, única revista oftalmológica mexicana indizada en Pubmed desde 1942 hasta 1986, año de la fusión de ambas revistas ${ }^{2}$, lo que la convierte en una de las revistas oftalmológicas más antiguas de Latinoamérica, y que mantuvo su publicación cuatrimestral durante ese periodo.

Además de esta importante contribución, la relación entre la RMO y la APEC se ha enriquecido con los innumerables artículos que han sido realizados y publicados por médicos del Hospital Dr. Luís Sánchez Bulnes, así como por algunos de los múltiples egresados de sus programas educativos y, finalmente, agregando lectores y revisores que nos han hecho crecer como revista.

Por todo esto, desde la RMO nos unimos a la celebración de estos primeros 100 años y esperamos seguir construyendo esta importante relación en los siguientes 100 años.

\section{Bibliografía}

1. Hernandez-Quintela E, Navas-Perez A, Garza-Leon M. Los primeros 120 años de la Revista Mexicana de Oftalmología. Rev Mex Oftalmol. 2018;92(5):225-6.

2. Catálogo electrónico del National Library of Medicine. Disponible en: https://www.ncbi.nlm.nih.gov/nlmcatalog?term=\%22Arch+Asoc+Evit+Ceguera+Mex\%22[Title+Abbreviation] 